\title{
A Universidade no limiar do século XXI"
}

ENSAIOS

\begin{abstract}
Antonio Manoel dos Santos Silva
SILVA, A. M. S. The institution of universities on the threshold of the $21^{\text {st }}$ century. Interface _ Comunicação, Saúde, Educação, v.3, n.4, 1999.

Given that the stimulation of reflection on the future of the university institution in its current historical moment is this paper's focus of concern, the author brings forth ideas from writers who represent various fields and trends, and who have been major sources of idea interchange where his personal reflections on the subject are concerned. Within this "composite of ideas", he provides a summarized description of the overall circumstances of universities in several countries, going into greater depth where the so called peripheral countries are concerned; he also raises possibilities that may arise or be closed to universities as they reach the threshold of the new century. He concludes his paper setting forth the dreams he has been nurturing relative to the future of the country, as well as pointing out paths that universities could take in the construction of this utopia.
\end{abstract}

KEY WORDS: university, education.

Tendo como preocupação central estimular a reflexão sobre o futuro da Universidade no atual momento histórico da instituição universitária, o autor traz à tona idéias de teóricos que, representando diferentes áreas e tendências, têm sido interlocutores importantes em suas reflexões pessoais sobre o tema. Nesse "arranjo de idéias", faz uma breve descrição da situação geral das universidades em diferentes países e, detendo-se nos chamados países periféricos, levanta as perspectivas que se abrem e se fecham para a universidade no limiar de um novo século. Conclui expondo sonhos que tem alimentado sobre o futuro do país e apontando caminhos para a universidade na construção dessa utopia.

PALAVRAS-CHAVE: universidade, educação.

\footnotetext{
* Palestra proferida no programa de Qualificação do Pessoal Docente para a Gestão Universitária, em 19/08/98, na sala do Conselho Universitário, Reitoria da UNESP.

${ }^{1}$ Reitor da Universidade Estadual Paulista - Unesp/SP.
} 
Muito, se não tudo, desta palestra, constitui um arranjo de idéias tomadas de vários autores. Não será falsa impressão se, ao ouvir-me, vocês sentirem que já leram alguma coisa idêntica ou semelhante em Drummond, Mário de Andrade, Mário Faustino, Eliade, Escotet, Albornoz, Giddens, Marcuse, Pedro Demo, Sérgio Buarque, Petitfils, Darcy Ribeiro, Adam Schaff e muitos outros, especialmente Souza Santos, que consultei mais. Misturo, portanto, poetas, cientistas políticos e sociais, educadores, filósofos, antropólogos e historiadores das mais diferentes e opostas tendências. Não vou ficar citando-os mas compensarei a falta de ostentação erudita indicando, no fim, a lista dos livros de que me servi nesta colagem.

Trata-se de falar da universidade num momento de preocupação com o seu futuro. Preocupação que vem motivada pelo fato de que se percebe, dentro da universidade, uma espécie de alienação crescente: verifica-se, de um lado, que os membros da comunidade universitária tendem a isolar a sua instituição dos problemas vividos e enfrentados pela sociedade e, por outro lado, nota-se uma perda de vínculos identificadores internos tanto quando se menosprezam os problemas específicos da administração universitária, como quando se levanta um distanciamento entre a figuração abstrata da Universidade e a própria vivência construída dela. Não é difícil deparar-se a cada momento com manifestações de professores, alunos e servidores técnicos e administrativos, em que cada qual, sendo da universidade, fala desta como se fosse uma entidade de que não fazem parte.

Começarei com uma pequena digressão, um tanto imaginária, seguida de breve apanhado sobre a situação geral em que as universidades, sem distinção de lugar, se encontram hoje tanto nos países qualificados como centrais quanto nos enquadrados como periféricos. Depois disso vou-me deter um pouco a estes últimos, apontando para as perspectivas que se abrem ou se fecham no limiar de um novo século. Encerrarei com a exposição de um sonho ou, se quiserem, de sonhos.

Como todos sabem, a palavra limiar, como quase todas as palavras, tem muitos significados. O básico é "soleira"; mas tem também outros bem comuns como os de "portal", "entrada", "patamar junto à porta". Interessa-me este sentido de espaço que precede a uma porta, porta que pode abrir-se, como umbral, a um espaço, que, neste caso, é um tempo que está por vir, o século XXI.

$\mathrm{Na}$ experiência quotidiana, vemo-nos muitas vezes em limiares: vestíbulo, sala-de-espera, sala de recepção, alguma vez já estivemos nesses lugares que nos preparam para a entrevista, para a audiência, para a consulta, para a cerimônia. Quando usamos a palavra limiar, evoco, portanto, um desses locais contíguos e fronteiros a outros que nos esperam.

Imaginemos, dentre estes locais, algum que nos seja desconhecido, como quando visitamos pela primeira vez uma clínica ou um consultório, no meu entender, espaços bem adequados para a representação. Estamos, então, sentados na sala-de-espera, e, dependendo do horário e da circunstância, estamos sozinhos. Nas paredes muitos posters, digamos posters de quadros de Van Gogh ou de impressionistas em exposição no museu d'Orsay; excepcionalmente uma cópia de gravura e, mais excepcionalmente ainda, um quadro primitivista. As cadeiras e poltronas são confortáveis, as mesas de 
canto suportam revistas, várias denotam uso, e uso nervoso. Estamos ali, apreensivos, não só por não saber o que há do outro lado desse limiar e quem vai abrir a porta. Estamos ali porque não sabemos o que vai acontecer depois.

Como nos limiares míticos e nos espaços simbólicos de preparação, ouvimos interiormente os augúrios, as predições do futuro e podemos até ler em algum letreiro escuro, como o que Dante leu no começo de sua reveladora aventura, palavras que anunciam a morada do sofrimento e da dor, da condenação e da ausência completa de esperança. Palavras que, com as devidas adaptações interpretativas, poderiam aplicar-se aos que, neste fim de século, pretendem avançar para o próximo.

Não temos, como Dante, a graça de um Virgílio que nos guie. Temos, porém, a tradição de Virgílio e de Dante, de filósofos e de historiadores de antes e de depois deles, de sociólogos e de economistas, de cientistas políticos e de utopistas. Temos toda a cultura crítica das universidades. Estamos, pois, em condições de esboçar cenários ou situações gerais para melhor nos localizarmos no limiar do século XXI. Até me arrisco a dizer que

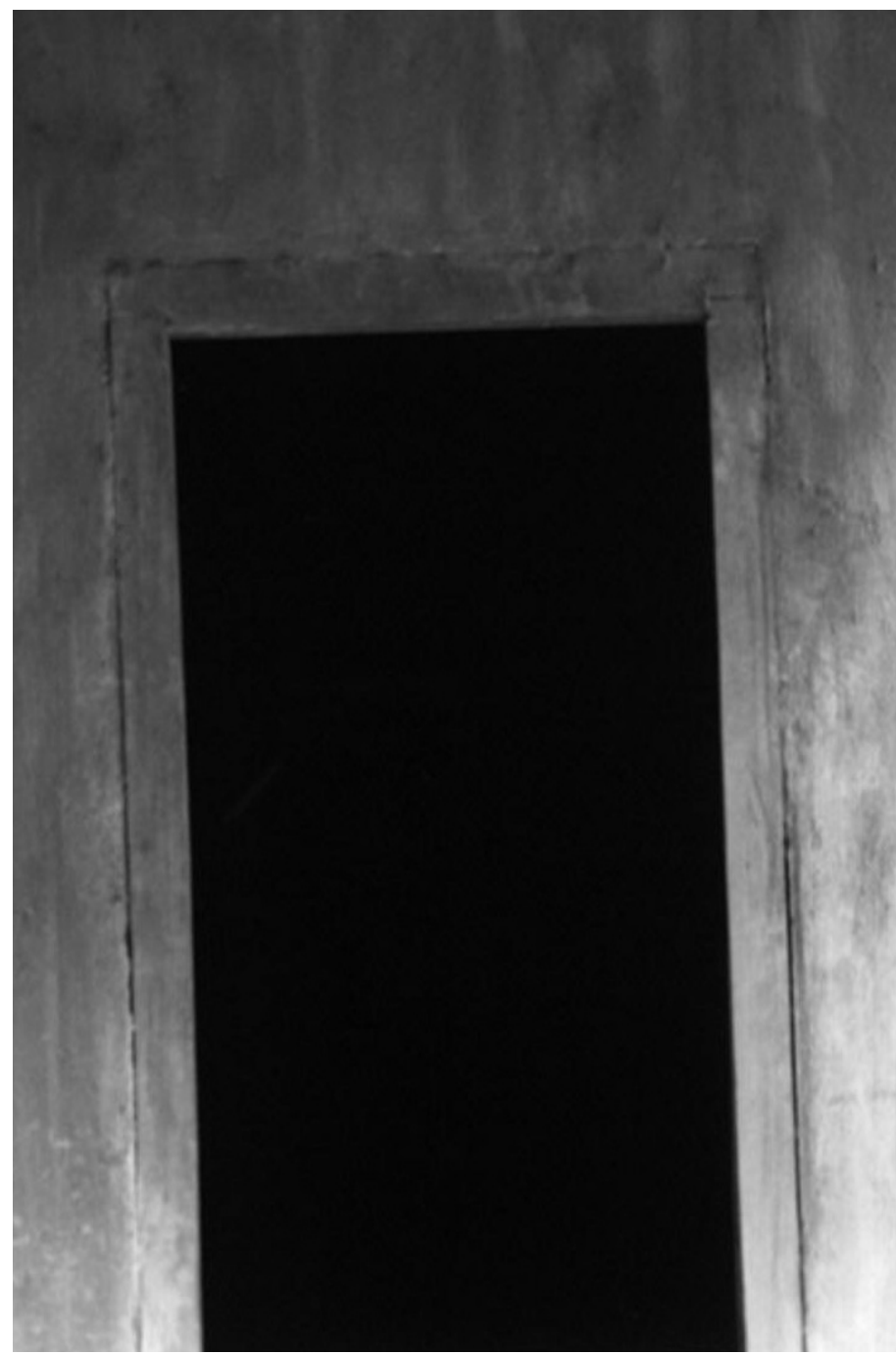
os traços fundamentais e importantes desse esboço já foram feitos por Boaventura de Sousa Santos em Pela Mão de Alice, livro cuja leitura recomendo como importante e que pode tornar-se base para reflexões sobre a situação e o destino das universidades. Vou segui-lo meio livremente.

A situação da universidade finissecular não pode ficar desvinculada da situação geral por que passa a humanidade inteira, não só por causas estruturais, mas porque as próprias universidades são fonte responsável $e$ geradora dessa situação geral. Os sociólogos e cientistas políticos concordam que as colunas que sustentam essa situação, a regulação $e$ a emancipação, fundam-se no Iluminismo, no século XVIII, sendo cada uma delas armada e constituída por três princípios, cujo equilíbrio, predominância ou subordinação definem a natureza da coluna (não custa imaginar aqui a analogia com uma coluna de concreto armado).

A coluna da regulação se forma, se organiza, se orienta, se dirige, se sustenta, se enfraquece ou se fortalece, conforme as circunstâncias, de acordo com a atuação ou do Estado, ou do 
Mercado ou da Comunidade, que são os seus três princípios determinantes. São determinantes da coluna da emancipação os princípios ou as lógicas da racionalidade moral-prática (ética e direito), da

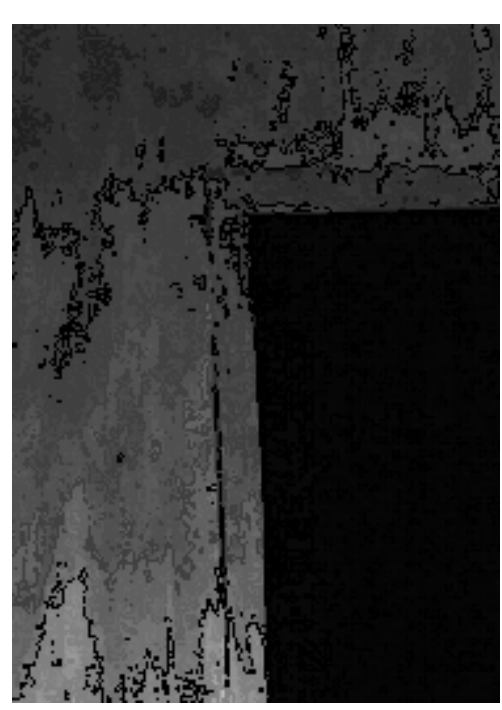
racionalidade cognitivo-instrumental (ciência $e$ técnica) e da racionalidade estético-expressiva (arte e literatura). Estes princípios da emancipação articulam-se, por correspondência e por predominância (isto é, sem exclusividade), com os da regulação, segundo a seguinte ordem: ética e direito com Estado, ciência e técnica com Mercado, arte e literatura com Comunidade. Os diferentes modos de correlação desses princípios definem as características desse fenômeno que nós, em linguagem menos técnica e mais difundida, costumamos designar como globalização.

Assim, no mundo atual, caracterizado como de predomínio da política neoliberal, mas também como de domínio do capitalismo financeiro, neste fim de século, nos deparamos com uma característica central: predomínio do princípio do Mercado sobre os do Estado e da Comunidade, com as instituições do segundo postas a serviço do primeiro e coagindo o terceiro. Tal relação de forças reflete-se nas lógicas correspondentes em termos de emancipação, a saber, sobreposição da racionalidade cognitivo-instrumental sobre a moral-prática e a estéticoexpressiva. Daí encontrarmos, neste limiar do século XXI, as seguintes características definidoras da situação geral da humanidade:

I Crescimento explosivo do mercado mundial, dominado pela tríade facilmente identificável: Europa Ocidental, Japão e Estados Unidos, não propriamente em virtude da força dos estados correspondentes, mas dos centros de especulação financeira neles instalados.

2 Tendência à neutralização, em escala mundial, das economias nacionais, que por sua vez vivem subordinadas e à deriva dos movimentos de especulação internacionais, sem capacidade de encontrar um roteiro dentro dessa "irracionalidade".

3 Debilitação dos mecanismos corporativos relativos ao controle ou à negociação de conflitos entre capital e trabalho. Freqüentemente, tal enfraquecimento reflete-se na incapacidade perceptiva quanto ao poder das forças em conflito, já que estas podem estar do mesmo lado do trabalho.

4 Precariedade crescente da manutenção salarial e da sua relação, não sendo rara a preservação do emprego à custa da diminuição do valor-hora.

5 Modernização da produção industrial por meio da automação, da automatização e da flexibilização dos processos produtivos; conseqüentemente, aumento de desemprego e criação de novos $e$ imprevisíveis tipos de emprego.

6 Industrialização dependente nos países periféricos, ainda que estejam em (difícil e dificultada) emergência.

7 Novas configurações de ocupação do espaço por causa da migração de indústrias e complexos industriais, da subcontratação internacional e, 
contraditoriamente, da vontade de recuperação da territorialidade (comunicabilidade, não fragmentação do humano, busca de melhor qualidade de vida): desindustrialização das cidades, industrialização do mundo rural, micro-urbanizações rurais etc.

8 Diferenciação dos produtos de consumo, incluindo os de alimentação $e$ vestuário, de modo que se particularizem os gostos e se aumentem as possibilidades de escolha.

9 Informatização e comunicação instantânea.

Todos esses traços se verificam quando olhamos o mundo atual desde a perspectiva do Mercado, que constitui o princípio prevalente. Se o olharmos, agora, da perspectiva do Estado, verificamos, primeiro, que este se enfraquece em sua atuação diante de algumas necessidades ou demandas sociais, que são direitos humanos e verdadeiros, como a saúde e a educação. Observa-se uma retração do Estado, por meio de seus governos, às políticas sociais. Os dirigentes perdem a capacidade ou a vontade política de responsabilizar-se por esferas da produção até mesmo estratégicas para o desenvolvimento social (privatizações). Do ponto de vista externo, verificamos em nós, à nossa volta em países vizinhos e também em outros mais distantes, a debilitação do Estado por força da adesão de diferentes governos à transnacionalização da economia.

Por outro lado, podemos notar outro fenômeno que reforça a subordinação crescente do Estado ao princípio do Mercado. Parece paradoxo formal, mas constitui real e histórica contradição, o fato de que o Estado se debilita na medida em que procura fortalecer-se por meio da transferência de responsabilidades e competências que não têm relação direta com os setores que os governos consideram essenciais, ou seja, os setores da própria e restrita administração de governo, melhor diria, de gerência de recursos. Há governos que tendem a governar-se a si mesmos, pela redução do Estado a eles próprios. Uma das conseqüências dessa redução consiste em identificar-se reforma administrativa com reestrutura de gestão; outra conseqüência é a multiplicação de microdespotismos burocráticos.

Vejamos agora, dentro deste quadro, como se sai o princípio da Comunidade, coagida pelo Estado que se mercantiliza. E neste caso convém ressaltar o surgimento de fenômenos de resistência, dialeticamente explicáveis, tais como as novas práticas de mobilização social. São movimentos orientados por reivindicações mais globais ou de caráter mais geral, como os da preservação da natureza, do pacifismo, do anti-racismo, do feminismo, do homossexualismo, notando-se neles, como não poderia deixar de acontecer, a amenização do discurso radical que caracterizou muitos movimentos sociais anteriores. Menos pasteurizados, porém, ainda que com os riscos do filtro homogeneizador e da absorção político-ideológica dominante, observam-se movimentos críticos e dirigidos para interesses de classes e de grupos excluídos.

Apesar disso, prevalece a adaptação, cujo resultado mais notável está no aumento astronômico dos setores de serviços. Ao mesmo tempo assiste-se à progressiva diferenciação $e$ ao fracionamento interno das classes trabalhadoras que vão caminhando para as subclasses e para a diluição. 
Talvez esta seja uma das causas da diminuição de sindicalizados, bem como do enfraquecimento do espírito de lealdade dos filiados a seus sindicatos: os interesses de classes vão-se substituindo por interesses corporativos $e$ individuais. Para completar, vão perdendo substância os conteúdos ideológicos dos partidos de esquerda, cujos discursos se amenizam e cujos apelos para a ação concreta vão-se transformando, principalmente em períodos eleitorais, em generalizações abstratas e aceitáveis pelas massas temerosas de inovações.

Quanto à emancipação, o princípio da racionalidade estético-expressiva se dá, neste limiar do século XXI, pela dissolução. Tudo que pode significar alta cultura ou criação original, mesmo coletiva, interpreta-se como sobrevivência do arcaico, como contaminação (uma impureza) ou, no melhor dos casos, como marginalidade. Essa dissolução, que se observa, no plano da crítica, no não entendimento do que seja alta cultura, se realiza por meio da rápida comercialização, por meio da distração impositiva e por meio da reprodutibilidade técnica. Muitos posters (por que não cartazes?) e poucos quadros. Também se observa no predomínio da técnica sobre a arte, do virtuose sobre o artista, do padrão venal sobre o criativo e instigante.

Também caracteriza a situação geral presente, a intensidade cada vez maior da modernização por meio da ciência e da tecnologia, com mais ênfase na tecnologia do que na ciência $e$ - isto se torna significativo - com a indução do desenvolvimento de ambas consoante os valores de mercado.

Em termos de vida social, o mundo finissecular mostra um ordenamento jurídico que põe às claras o divórcio entre alguns valores da modernidade, como a autonomia $e$ a subjetividade, $e$ as práticas políticas $e$ quotidianas. Incrementam-se regulamentações jurídicas que se auto-alimentam e se multiplicam, dando origem a novas regulamentações, que dêem conta das primeiras. Por fim, neste campo da racionalidade moral-prática, assiste-se hoje ao problema grave da dissolução ética que consiste no confinamento cada vez mais estrito dos seres humanos em individualismos intransponíveis. Assim - e contrastando - se vemos hoje emergirem, positivamente, novos direitos e novas idéias de solidariedade, vemos igualmente, e de modo violentamente destrutivo, tornar-se valor predominante a competitividade.

Em resumo, a situação geral se caracteriza por isso que nós hoje vulgar e banalmente chamamos de globalização, entendida esta como desenvolvimento fundado no eixo da economia de mercado e cujos aspectos mais visíveis são os que se seguem: interdependência tramada pelas leis do mercado financeiro; concentração dos fios dessa trama em três regiões nodais do planeta - EUA, Japão e Europa Ocidental - com seus pontos cegos nas Bolsas de Valores, principalmente as de Nova York, Tóquio e Londres; criação e integração de grandes mercados regionais (Nafta, Mercosul, Mercado Comum Europeu); operações financeiras fortemente rápidas; informação em tempo real; competitividade; transformação do conhecimento em valor econômico (mercado do conhecimento); $e$ aprofundamento das assimetrias sociais.

Jamais o mundo foi tão rico, mas nunca foi tão iníquo como neste fim de século. Os países centrais detêm cerca de $90 \%$ do intercâmbio econômico e 
$80 \%$ do dinheiro mundial. Os outros, considerados periféricos, ficam com o restante. Esta assimetria global ganha a forma de grandes assimetrias sociais nas regiões não favorecidas pelo desenvolvimento econômico mais acentuado. Assim, no Brasil, considerado uma das maiores economias do mundo, apenas $7 \%$ da população desfrutam ou têm condições de desfrutar dos bens produzidos com essa riqueza, $70 \%$ situam-se entre os níveis de pobreza e da mais completa miséria. Deste modo não se exagera quando se qualifica essa situação como de iniqüidade.

Os países periféricos têm-se tornado fonte de subcontratações ou de alto lucro para as empresas sediadas nos países centrais; mas têm-se tornado também fonte de preocupações, na medida em que o atraso pode irromper em movimentos de rebeldia, em migrações incontroláveis e em retorno a sistemas de governo ultraconservadores. Ao mesmo tempo se propaga a modernização reflexa não apenas nas artes e na literatura, mas nos costumes e na cultura, incluindo aquela parte da cultura que se faz por consumo e que se traduz em valores de vivência e de convivência (esportes, formas de lazer, vestimenta, culinária, música popular massificada etc.). Essa homogeneização denota empobrecimento cultural.

Finalmente, muitos países periféricos tentam diminuir a distância científica e tecnológica que os separa dos países centrais. Neste afã de modernização acabam por reproduzir métodos, técnicas, processos $e$ resultados. Daí, o que constitui ativa racionalidade tecno-científica em regiões avançadas, nas demais se torna passiva recepção. Este é um ponto fundamental para as universidades.

As universidades estão entre as instituições mais antigas e conservadoras que o Ocidente criou, consolidou, manteve e expandiu. Talvez por causa dessa antigüidade e desse conservadorismo, são as que mais sentem a inversão da ordem que torna o Mercado o princípio que se sobrepõe aos demais princípios da regulação. Por ironia histórica, deveriam estar preparadas para a nova ordem, uma vez que ajudaram a engendrá-la, se não constituem elas mesmas a fonte que lhe deu origem.

De fato muitas são as crises por que passam as universidades. Boaventura de Sousa Santos, no livro já citado, sintetizou-as em três: a crise de hegemonia, a crise de legitimidade $e$ a crise institucional. A primeira deriva da tensão entre conhecimentos exemplares $e$ conhecimentos funcionais, $e$ atinge o núcleo da missão constitutiva da universidade. A segunda se origina da tensão entre hierarquização e democratização, perturbando o núcleo de sua destinação. A terceira

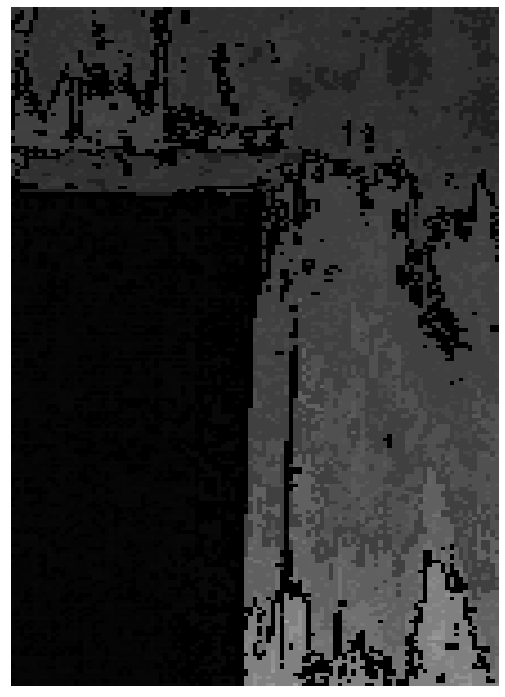
constitui resultado da tensão entre autonomia $e$ produtividade social, e abala as relações com sua estrutura de sustentação.

As universidades, principalmente quando pensadas como uma abstração maiúscula (a Universidade), sempre se qualificaram como templo do saber ou, mais humildemente, como o lugar privilegiado do conhecimento, tanto no sentido de que este ali se produz, quanto no sentido de que ali se 
mantém sob o crivo crítico e assim se pode difundir. Assim, são verdadeiros e exemplares os conhecimentos produzidos, mantidos e reconhecidos pela universidade.

Esta chancela está sendo posta em questão. A exemplaridade do conhecimento não se considera mais como algo exclusivo ou único ou necessário, desde já algum tempo. Essa profanação, ou melhor, essa contestação repercute no interior das universidades (e na relação destas com o exterior) por meio do conflito entre alta cultura $e$ a cultura popular $e$ entre ambas e a cultura de massas. Repercute igualmente no conflito entre instrução e formação, entre adestramento e educação. Faz-se sentir também na oposição entre teoria e prática, fato que no Brasil se agrava graças ao problema cultural do preconceito relativo ao trabalho manual e a tudo que com ele se relaciona.

Esta mesma tensão entre exemplaridade e funcionalidade nota-se no tratamento diferente dado à pesquisa básica e à pesquisa aplicada; para aquela se contabilizam custos e para estas, benefícios e recursos. Por último, a exemplaridade e a funcionalidade balizam as opções por atendimento às demandas da sociedade: demandas verdadeiramente sociais, tanto físicas quanto espirituais, e demandas de mercado, cujo fundamento é o lucro.

Quanto à crise de legitimidade, começamos a percebê-la quando nos indagamos sobre a missão fundamental, a destinação primeira da universidade. A resposta unânime: a missão fundamental da universidade é a formação de seres humanos. Logo depois da resposta, a dúvida: as universidades têm cumprido seus compromissos coletivos? E não há quem, em sã e honesta consciência, consiga suspender a dúvida por meio de afirmação positiva. A tensão que gera essa crise verifica-se na exclusão de grande parte da coletividade ou na incorporação muito limitada de grupos marginalizados, verifica-se na oposição entre seletividade e não seletividade, acesso por meio de vestibular ou por avaliação progressiva.

Esta segunda crise se manifesta também

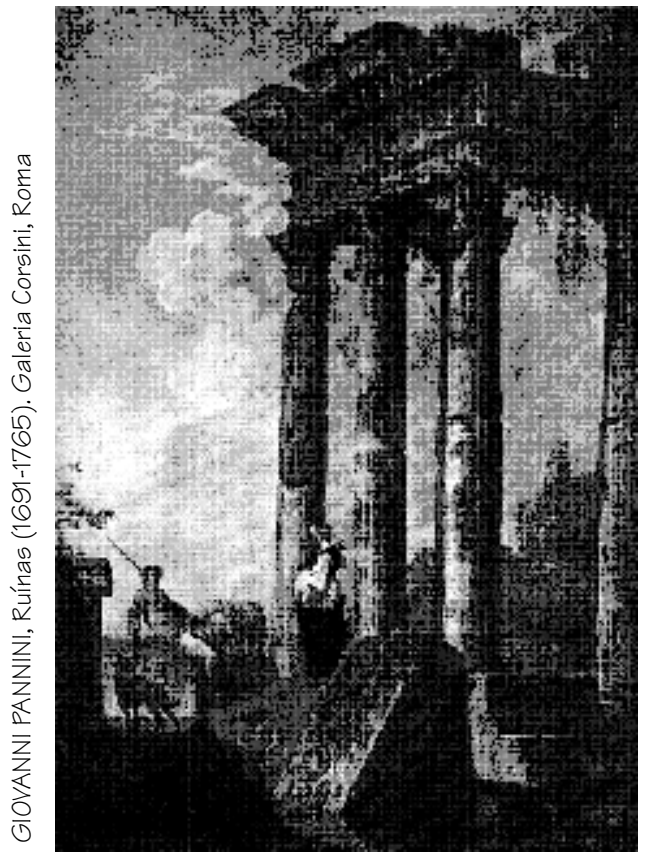
nas hierarquizações e classificações (rankings) de universidades, institutos, faculdades e cursos, bem como em todas as tentativas de transformar o sistema universitário num aglomerado de centros dedicados: aqui universidades de pesquisa, ali universidades de ensino, acolá, de extensão $e$, meta das metas, universidades de prestação de serviços em toda parte.

A crise institucional, que se configura na tensão entre autonomia e produtividade social, talvez seja a mais perturbadora, já que seus sintomas (bem como os diagnósticos $e$ remédios propostos) têm-se tornado, de uns tempos para cá, objeto de ampla divulgação, freqüentes conversas e debates de camuflada profundidade.

O seu aspecto mais pesado e dramático

18 Interface - Comunic, Saúde, Educ 4 
apresenta-se nas recentes políticas de financiamento, que contrastam com as demandas do Estado e da sociedade. Estas crescem, enquanto os orçamentos encurtam ou, no melhor dos casos, estacionam. Cria-se, por causa disso, a impressão de que as universidades não correspondem aos recursos que o Estado lhes destina, não produzem, isolam-se da comunidade e não atendem, por incompetência ou por elitismo, às exigências da sociedade (que se entende geralmente como o mercado).

Esta crise internaliza-se na universidade pública por meio de conflitos distintos e variados, que se revelam tanto nos discursos que representam as instituições quanto nos discursos das corporações, desdobrando-se, por outro lado, no conflito entre estes e sua prática. Um deles se faz presente na inconciliável superposição de concepções coexistentes na identificação da universidade, cuja natureza se pretende seja ora social, ora funcional, ora gerencial. Outro está na defesa da autonomia ilimitada (ou limitada apenas pelo estatuto constitucional) e a rejeição de qualquer tipo de acompanhamento e controle social. Um terceiro consiste em defender ( $e$ defender com intransigência) o caráter público da universidade mas aceitar, com conivência ou conformismo, a privatização dos serviços por meio de Fundações de Direito Privado.

Enfatizando que a privatização do público constitui a face mais escandalosamente encoberta da crise institucional de algumas universidades sustentadas pelo Estado, $e$, por esta razão, a fissura mais grave em sua natureza e finalidade, a tensão que lhe é inerente tem outros lados mais visíveis: o da privatização paralela, o da competitividade com as universidades privadas, o da importação de estruturas administrativas $e$ organizacionais forâneas (comerciais, industriais e financeiras, por exemplo), $e$ todas, repito, todas as avaliações de desempenho que preferem os resultados quantificáveis aos processos qualificáveis.

Nos países menos desenvolvidos, como o Brasil, as tensões acima resumidas e brevemente comentadas acontecem num grau maior ou mais intensamente. O risco maior para as universidades destes países é o de se transformarem elas em centros de reprodução acrítica de ciência (pode ser assim chamada?) e de tecnologia, que constitui a força mais dissolvente da globalização e do fenômeno da modernização reflexa. Essa adesão ao desenvolvimento fundado no eixo do mercado, verifica-se com muita clareza nos seguintes e principais pontos:

1 "produção" de conhecimentos e de técnicas em função das demandas de mercado;

2 concepção de ensino como adestramento;

3 busca, no mercado científico internacional, de lideranças em pesquisa $e$, obsessiva e exclusivamente, de padrões internacionais de julgamento;

4 envio, aos países centrais, de lideranças científicas potenciais (conseqüentemente, estímulo à evasão de cérebros);

5 estabelecimento de intercâmbios isolados com núcleos de excelência científica dos países altamente desenvolvidos;

6 arremedo de laboratórios de ponta (de ponta nos países do primeiro mundo). 
Uma adesão irrestrita $e$ não refletida ao fascinante mundo superdesenvolvido, torna a universidade de país periférico semelhante ao herói plano ou superficial que, sob as ordens de um destinador onipotente, cumpre sua missão sem pestanejar, enfrentando todas as dificuldades ogros, dragões, bruxas e feras, inimigos terríveis - sendo favorecido com o casamento com a filha do rei, com parte do reinado ou com o prêmio da riqueza ou do prestígio. Deve comportar-se a universidade brasileira como um herói domesticado?

Se adotasse aqui a postura de uma representatividade neutra, diria que a universidade pode sucumbir a essa adesão. Entretanto, vou-me afastar dessa neutralidade, misturando escolha ideológica e um pouco de reflexão realista.

Acredito que as universidades do mundo não desenvolvido têm que resistir ativamente contra a situação geral que vivemos no final do século $X X$, em pleno capitalismo financeiro ou, se quiserem, em plena época de desenvolvimento centrado no eixo exclusivo do mercado. Acho que essas universidades não podem aderir; acho que devem resistir de forma positiva. Advogo, pois, uma resistência positiva.

Isto significa para mim que as universidades brasileiras devem ter a percepção realista de que o processo de globalização se fortalece cada vez mais em torno do eixo estritamente econômico e de mercado, não dando sinais de enfraquecimento e causando profundas inquietações regionais $e$ às vezes até turbulências sociais. Todos os acontecimentos recentes que perturbaram a economia mundial, ao contrário de indicarem algum desvio dessa rota desenvolvimentista específica, apenas confirmam o roteiro.

As universidades têm de perceber este fato, assim como têm de perceber emergências não previstas nesse processo de desenvolvimento, emergências que dialeticamente contradizem a globalização e os princípios que a fundamentam, a começar da irracionalidade que marca os movimentos da especulação financeira internacional.

Emerge uma sociedade civil global, ligada por meio de tecnologias comunicativas, que evoluem com base na informação compartilhada e que possibilitam a crescente consciência de identidades diferenciadas e de culturas locais e regionais. Desse modo, vai-se verificando uma espécie de participação global que, em vez de anular o específico, chama a atenção para este.

Ao mesmo tempo, pode-se perceber que hoje se está formando uma nova consciência coletiva - nem sempre crítica -, mais ampla talvez, sobre a importância da natureza, das culturas nacionais, da solidariedade entre os povos e entre as sociedades. Surgem também propostas de novos estilos de vida que visam à distribuição mais justa dos recursos naturais e da riqueza. Sente-se que o sentimento de solidariedade geral pode impulsionar o desenvolvimento humano para formas globais de intercâmbio, para o florescimento de diversas culturas e para o diálogo de culturas excluídas ou marginais com a alta cultura da racionalidade científica e tecnológica.

Finalmente, pode-se descobrir, neste final de século, a permanência e o cultivo de utopias conciliatórias: conciliação entre a preservação da autonomia com as exigências da solidariedade, $e$ incorporação de processos de modernização internacionais, por meio de adaptações e transformações, 
para a solução de necessidades locais.

Por tudo isso, que perspectivas de resistência positiva se abrem para a universidade brasileira hoje? Ouso responder que as seguintes:

I a recepção crítica da ciência e da tecnologia produzida nos países centrais;

2 a reversão tecnológica, ou seja, a desmontagem, transformação ou adaptação das tecnologias em função de nossas carências e realidades;

3 a orientação de nossos esforços de ensino e de pesquisa para as necessidades sociais, sentidas ou não sentidas, o que implica sensibilidade $e$ antena para problemas de pobreza ou de carência material, espiritual, intelectual e ética;

4 diversificação de visões, interpretações $e$ instrumentos de intervenção, por meio de enfoques comparativos, de estudos internacionais e interculturais, de projetos interinstitucionais e inter-regionais, enfim, por meio da recusa à homogeneização.

E completo dizendo que essa resistência positiva pede a adoção de estratégias acessíveis, algumas das quais imprescindíveis: o ensino fundado na construção do conhecimento e enraizado na história e na experiência concreta; a criação e o desenvolvimento de programas de pós-graduação abertos, isto é, estruturados em níveis permeáveis e com entradas independentes; o domínio de linguagens, incluindo o domínio da língua portuguesa; a criação de redes regionais, nacionais e internacionais de pesquisa; $e$ a utilização de intercâmbios eletrônicos e educativos.

A universidade resistente se configura aqui como um herói problemático, ou seja, como aquela personagem que busca, num mundo inautêntico e degradado, mesmo que seja por meios inautênticos ou degradados, valores autênticos. $\mathrm{O}$ destinador desse herói problemático seria o ideal de uma sociedade justa e sua ação incidiria sobre a sociedade iníqua, que deve transformar-se a despeito desse grande e feroz oponente que é a mão invisível e opressiva do mercado. Se acreditarmos nesta possibilidade de resistência positiva, teremos muito que fazer, já que não será fácil gerenciar tensões.

Chego assim à terceira e última parte de minha palestra. A do sonho, e que, estando motivada pelas considerações anteriores, contém algo de nostalgia $e$ de mito. Esta parte final parece traduzir o ideologema que se concretizou culturalmente - e por séculos - na fórmula do Brasil, país do futuro; mas também parece comportar a visão edênica num momento - fim de século propício ao florescimento, ainda que camuflado, da imagem da renovação e do começo de uma nova história. Parece ambas as coisas. Mas não é. Pois estamos diante do século XXI. Dois corredores possíveis nos esperam depois que a porta se abrir.

Que será o futuro século? Será o da fusão entre utopia e paraíso perdido? Se for assim, que canteiro desse vasto jardim do mundo o Brasil vai ocupar?

Será por acaso, o século XXI, um século a tal ponto globalizado que as diferenças regionais $e$ as identidades nacionais emergirão apenas como lembranças de um bárbaro século $X X$, dividido entre nações e tribos, religiões $e$ seitas, línguas e dialetos, privilegiados e miseráveis, inseridos e excluídos, terras arrasadas e reservas ecológicas? Haverá sentido em falar de Brasil e de universidade nesse país, que estará num mundo indiferenciado e sem tensões 
históricas?

Entretanto o tema desse sonho, tal como é imaginado, pressupõe a existência de uma nação chamada Brasil e, implicitamente, as diferenças e os conflitos. Além disso pressupõe, como sonho, o objeto de desejo coletivo, se sonho coletivo. Que Brasil queremos, para saber que universidade seremos?

A menos que o individualismo mais solipsista e a competição mais destrutiva tenham levado os homens à total cegueira e ao ceticismo feroz, a resposta a essa interrogação vem sendo dada em todas as entrevistas de rua que se prolongam em outros discursos com maior ou menor aprofundamento, com sutilezas tecno-verbais ou avaliações mais complexas.

Queremos um país em que todos possam viver felizes. Um país em que todos se sintam seres humanos de verdade. Eis uma resposta geral e de qualquer tempo e para qualquer tempo, tão universal como uma aldeia. Poetas brasileiros deste século $\mathrm{XX}$, sob o signo do universalismo ou do particularismo, já exprimiram este desejo, sem para isso retornarem aos sonhos românticos ou ufanistas do século XIX.

Mário de Andrade idealizou uma terra de convívio fraterno, sem trabalho penoso: uma civilização solar em que a preguiça não tivesse a marca do pecado. Mário Faustino, morto tão jovem, ora projetou a cidade exata, aberta e clara, onde os contrários se conciliam, ora construiu, com imagens visionárias, um lugar de perene manhã, lugar este modelado e sustentado pelo cultivo das artes e das ciências fundidas no mesmo fazer humano. Carlos Drummond de Andrade projetou o país tecido pelo fio da convivência das diferenças regionais, país assinalado pela tolerância das diferenças; sem repressão da liberdade, sem grades e sem fronteiras. Se de fato nossos poetas exprimem o que queremos para o futuro do Brasil, exprimem o universal desejo de realização dos nobres ideais da fraternidade, da igualdade, da liberdade, da justiça e da paz: universalismo, autonomia $e$ individualismo coletivamente sustentado.

Poder-se-ia contestar a tais poetas que eles manifestam, sob diferentes cores ideológicas, aspirações vagas demais, mas são aspirações que se traduzem concretamente hoje pelo seu inverso, ou seja, pela exposição de necessidades e de carências de toda ordem. No fundo, os poetas - e nós com eles - desejamos que no século XXI o Brasil seja a negação da não liberdade, da não justiça, da não fraternidade, da não igualdade, da não paz, negação, enfim, de toda negação.

Caberia saber quais caminhos trilhados por nós vão-nos conduzir a esse futuro e, nos limites de uma faixa institucional, a faixa da educação superior, saber o que se pode fazer para constituir esse futuro, quer seja carimbado pela marca da produtividade e da competitividade, cuja bandeira é a inserção no primeiro mundo, quer seja ele o resultado possível da busca dentro dos conflitos históricos previsíveis de uma civilização amadurecida por meio de projetos realizáveis e em função de uma sociedade menos hierarquizada, menos dividida, menos fragmentada e iníqua e mais humana.

O primeiro caminho tem como ponto-de-chegada o primeiro mundo para onde vai o primeiro corredor após a porta da sala-de-espera em que nos imaginamos estar. O roteiro dessa viagem é conhecido, e se trata de percorrer a trajetória que vai do subdesenvolvimento ao desenvolvimento 
pleno. Assim, o Brasil do século XXI, será o país com os níveis de crescimento econômico e de bem-estar que os países centrais tenham atingido. Está claro que, ao visualizar esse primeiro mundo, se faz uma assepsia. Configura-se um espaço uniforme e limpo, como se todos os viventes desse espaço usufruíssem por igual, e com iguais oportunidades, das riquezas materiais $e$ dos produtos derivados da alta tecnologia.

Esquece-se de seu belicismo, de suas sofisticadas estruturas de dominação econômica, de seus nichos de miséria e de preconceito, da desumanização dos aglomerados urbanos, da poluição e da degradação ambiental, da ação destrutiva próxima ou distante sobre outros países e suas condições de vida. Concomitantemente, esse mundo de delícias fica fossilizado no futuro, como se no século XXI não estivesse ele assentado em outras bases. Assim abstrato e suspenso, coloca-se como medida de nosso progresso e de nosso desenvolvimento.

Em função dele somos chamados, convidados, incitados, convocados, pressionados e obrigados a aceitar uma nova ordem em que se dá mais valor à produção e à circulação de bens do que aos criadores e aos usuários dos mesmos. O defensor desse modelo desejável de sociedade futura descobre com acerto a importância da educação, tanto fundamental quanto média $e$ superior, embora a conceba como instrumento de produção de recursos humanos, exigidos pelas demandas econômicas do país.

Nem se poderia conceber a educação de forma diferente, uma vez que, nesse cenário de desenvolvimento, domina o esquema do desempenho e da produtividade, cuja estrutura determina a elaboração de mensurações, em que os enfoques quantitativos direcionam as avaliações, os planejamentos lineares e as projeções de custo e benefício.

Percebe-se hoje com facilidade a multiplicação de discursos, programas e propostas em que se estabelece relação direta de produtividade, competitividade e avaliação quantitativa com os níveis de educação e de instrução da força de trabalho, usando-se exemplos internacionais, inclusive asiáticos. Nossas referências de políticas (ou de falta de políticas) educacionais operam com correspondência de alto grau de escolarização com muito lucro, correspondência entre taxas de investimento em educação e resultados positivos de outros tipos de investimentos. Na prática, as próprias universidades, neste limiar de século XXI, se vêem metidas no campo da competição de quantidades: número de alunos por docente, número de alunos por funcionário, número de trabalhos publicados, número de citações em revistas de circulação internacional, pesquisadores mais produtivos, capacidade de captação de recursos junto a empresas e a órgãos de fomento etc.

E tendo em vista que o primeiro mundo não fica esperando o cumprimento de nossa trajetória, as necessidades presentes forçam planificações lineares de curto e médio prazos, gerando um ritmo de constante mudança. Feitos em função das necessidades de mercado, esses planejamentos visam à produção de recursos humanos qualificados pelo sistema formal ou, com outras palavras, exigem do sistema formal de educação um padrão de qualidade medido pelo mercado, dá prioridade à formação de profissionais e técnicos e se organiza por meio de estratégias 
preferencialmente voltadas para carências imediatas de empresas, geralmente privadas.

Acontece, porém, que no próprio primeiro mundo, refletindo-se dramaticamente no terceiro, que lhe vai a reboque, os planejamentos lineares e sua prática levam à diminuição da qualidade da educação, pois o sistema formal em que se apóia a fábrica de recursos humanos, incentiva o ganho de prestígio e de sucesso, quando não a posse de certificados, diplomas ou títulos. A esta substituição da busca do conhecimento pela busca de certificados, soma-se outra contradição: a prioridade dada à formação de recursos profissionais e técnicos, para atendimento das necessidades da economia, acaba gerando estoques de recursos que se vão deteriorando e se inutilizando nos armazéns de profissionais. Deste modo assistimos hoje, tanto no primeiro mundo, como no nosso, ao crescimento de profissionais diplomados sem emprego ou de profissionais com diploma empregados em trabalhos para os quais não foram adestrados.

Por fim, o ciclo formal de educação que projeta um futuro premido pelas necessidades imediatas, ao durar mais de década e meia, acaba preparando profissionalmente os homens do século XXI, segundo objetivos e necessidades ultrapassados.

São essas umas poucas contradições de tantas que nos afetam no plano da educação superior, se agimos em função de um Brasil do século XXI, modelado pela imagem ou forma do primeiro mundo.

Voltemo-nos agora a outro projeto futuro - entrando no segundo corredor - a outro Brasil desejado e tendo sempre em mente a natureza instável de qualquer previsibilidade.

Sintetizando grosseiramente nosso múltiplo e plural querer, imaginamos um país em que a economia estará organizada em função da justiça social: todos terão igualdade de direitos e de oportunidades, emprego garantido $e$ trabalho não penoso, trabalho que ajudará no provimento de moradia, vestimenta $e$ alimentação adequada $e$, se houver abundância de bens, isto acontecerá sem que parcela da população sinta alguma falta deles. Serviços públicos, como saúde e educação, serão gratuitos. Estarão em curso algumas superações: superação da divisão entre o produtor e o produto de seu trabalho, superação da ruptura entre as necessidades humanas sentidas $e$ não sentidas, conscientes $e$ inconscientes.

De modo geral, na sociedade brasileira do Século XXI, as regras e as condutas de sobrevivência humana se sobreporão e regularão a todo excesso de individualismo; as técnicas estarão subordinadas ao conhecimento e, sob o consenso coletivo de que há limites e constrangimentos reais que garantem a sobrevivência humana e sua harmonia com a natureza, o homem brasileiro será tanto sapiens quanto faber, um autocreator do desenvolvimento tecnológico de um universo globalizado. Trata-se de utopia, porém não de uma utopia regressiva que sublima a nostalgia num paraíso perdido, se contenta com a contemplação e, pessimista, exclui toda esperança, vale dizer, toda ação humana em busca de um bem futuro. Digamos tratar-se de uma utopia concreta que projeta um futuro segundo um conhecimento sem dúvida imperfeito das tensões e das contradições 
históricas presentes e que pede o compromisso de todos.

Aqui também a educação superior desempenha um papel central como instrumento que tornará possível o novo país. Uma educação que, todavia, toma os seres humanos completos como eixo do desenvolvimento ou, se quiserem, do progresso. A tarefa consiste em formar o homem no conhecimento de si mesmo e das circunstâncias que o tornam homem: natureza, sociedade e cultura herdada; consiste igualmente em situar esse homem na sua dimensão política de sujeito e objeto de desenvolvimento, integrado ao processo de construção de um novo país, correlacionado, por sua vez e integradamente, a outras nações.

Essa educação requer planejamento que, articulando objetivos de curto $e$ médio prazos, integre-se com políticas mais duradouras, ainda que flexíveis, em função de uma ainda-não sociedade. Implica, no presente, ações orientadas para a democratização, para a inovação e para o desenvolvimento autônomo. Cada uma destas orientações demanda estratégias com programas realizáveis dentro de nossas limitações. No caso da universidade orientada para a democratização, pensemos na diversificação e na expansão do sistema com programas de fomento da participação popular e da educação à distância. No caso da orientação para a inovação, pensemos no campo da educação informal com os programas para desenvolvimento das comunidades urbanas e rurais ou, no campo da educação formal com a criação de instituições de educação superior aberta.

E no caso da orientação para o desenvolvimento autônomo, pensemos no estabelecimento da rede de centros nacionais de pesquisa de que participariam as universidades ou, para encerrar esta lista de sugestões, pensemos nas estratégias de cooperação internacional em ciência e cultura.

Estes são alguns horizontes do sonho que se abre para a Universidade de hoje, em função do Brasil que podemos imaginar no século XXI, desde este fim de século, seu limiar.

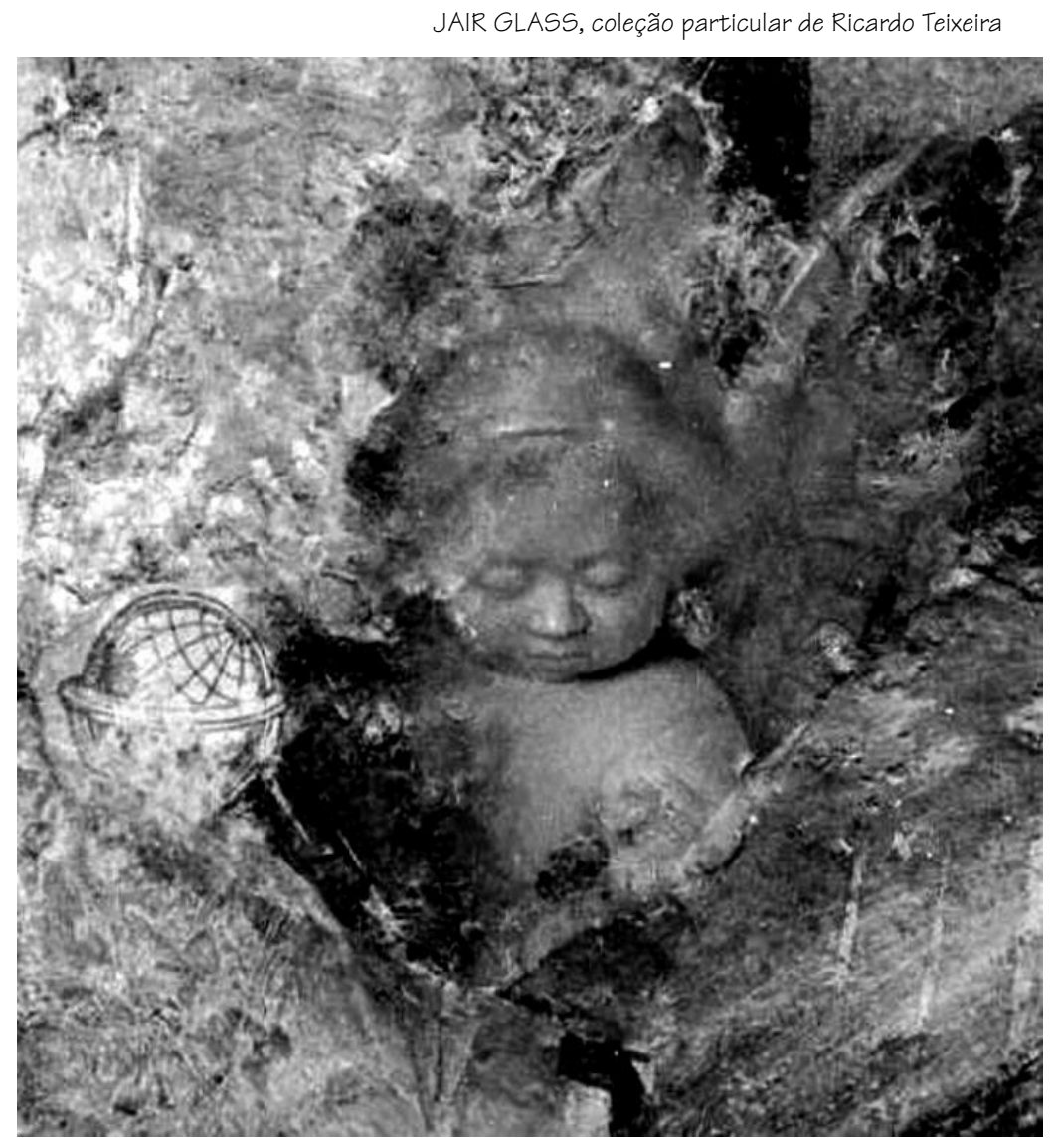

fevereiro, 1999 


\section{Referências bibliográficas}

ANDRADE, C. D. Poesia e prosa. 5.ed. Rio de Janeiro: Nova Aguilar, 1979. ANDRADE, M. Poesias completas. Belo Horizonte: Itatiaia, 1987.

DEMO, P. Desafios modernos da educação. Petrópolis: Vozes, 1993.

ELIADE, M. La nostalgie des origines: methodologie et histoire des religions. Paris: Gallimard, 1971.

ESCOTET, M. A., ALBORNOZ, O. Educación y desarrollo desde la perspectiva sociológica. Salamanca: Ed. Universidad Iberoamericana de Postgrado, 1989.

FAUSTINO, M. Poesia completa: poesia traduzida. São Paulo: M. Limonad, 1985.

GIDDENS, A. As conseqüências da modernidade. São Paulo: EDUNESP, 1991.

HOLANDA, S. B. Visão do paraíso: os motivos edênicos no descobrimento $e$ colonização do Brasil. 4.ed. São Paulo: Ed. Nacional, 1985.

MARCUSE, H. Eros and civilization. 9.ed. Boston: Beacon Press, 1966.

MORAIS, R. Filosofia da ciência e da tecnologia: introdução metodológica $e$ crítica. 5.ed. Campinas: Papirus, 1988.

PETITFILS, J. C. Les socialismes utopiques. Paris: PUF, 1977.

REVISTA EDUCACIÓN SUPERIOR Y SOCIEDAD. Caracas: UNESCO, CRESALC, V.6, n.1, 1995.

RIBEIRO, D. O processo civilizatório: etapas da evolução sócio-cultural, estudos de antropologia da civilização. São Paulo: Círculo do Livro, 1978.

ROUANET, S. P. Mal-estar na modernidade. São Paulo: Companhia das Letras, 1993.

SANTOS, B. S. Pela mão de Alice: o social e o político na pós-modernidade. 3.ed. São Paulo: Cortez, 1997.

SCHAFF, A. A sociedade informática. 4.ed. São Paulo: EDUNESP, 1993.

UDUAL. La Universidad latinoamericana en el fin de siglo: realidades $y$ futuro. Mexico: UDUAL, 1995.

VESSURI, H. M.C. La Academia va al mercado: relaciones de cientificos academicos com clientes externos. Caracas: FINTEC, 1995.

SILVA, A. M. S. La universidad en el umbral del siglo 21. Interface _ Comunicação, Saúde, Educação, v.3, n.4, 1999.

Teniendo como preocupación central estimular la reflexión sobre el futuro de la universidad en el actual momento histórico de la institución universitaria, el autor pone de relieve ideas de intelectuales que, representando diferentes áreas y tendencias, han sido interlocutores importantes en sus consideraciones personales sobre el tema. En esta "composición de ideas" hace una breve descripción de la situación general de las universidades en diferentes países $y$, deteniéndose en los llamados países periféricos, levanta las perspectivas que se abren y se cierran para la universidad en el umbral de un nuevo siglo. Concluye exponiendo sueños que ha alimentado sobre el futuro del país y apuntando caminos para la universidad en la construcción de esta utopía.

PALABRAS-CLAVE: universidad, educación. 